OPEN ACCESS

Edited by:

Agata Gadaleta,

Università degli Studi di Bari Aldo

Moro, Italy

Reviewed by:

Fernando Martinez,

University of Seville, Spain

Antonio Blanco,

Università degli Studi di Bari Aldo

Moro, Italy

*Correspondence:

Tianheng Ren

renth@sicau.edu.cn

Zhi L

lizhi@sicau.edu.cn

Specialty section:

This article was submitted to Crop Science and Horticulture,

a section of the journal

Frontiers in Plant Science

Received: 23 January 2017 Accepted: 28 April 2017

Published: 15 May 2017

Citation:

Ren T, Tang Z, Fu S, Yan B, Tan F,

Ren $Z$ and Li Z (2017) Molecular

Cytogenetic Characterization of Novel

Wheat-rye T1RS.1BL Translocation

Lines with High Resistance

to Diseases and Great Agronomic

Traits. Front. Plant Sci. 8:799

doi: 10.3389/fpls.2017.00799

\section{Molecular Cytogenetic} Characterization of Novel Wheat-rye T1RS.1BL Translocation Lines with High Resistance to Diseases and Great Agronomic Traits

\author{
Tianheng Ren ${ }^{*}$, Zongxiang Tang1, Shulan Fu', Benju Yan', Feiquan Tan', \\ Zhenglong Ren ${ }^{1}$ and $\mathrm{Zhi} \mathrm{Li}^{2 *}$
}

${ }^{1}$ Agronomy College, Sichuan Agricultural University, Sichuan, China, ${ }^{2}$ College of Life Science, Sichuan Agricultural University, Sichuan, China

Rye has been used worldwide as a source for the genetic improvement of wheat. In this study, two stable wheat-rye primary T1RS.1BL translocation lines were selected from the progeny of the crossing of the wheat cultivar Mianyang11-1 and a Chinese local rye variety, Weining. These two novel translocation lines were identified by molecular cytogenetic analysis. PCR results, multi-color fluorescence in situ hybridization (MC-FISH), and acid polyacrylamide gel electrophoresis (A-PAGE) indicated that both new translocation lines harbor a pair of T1RS.1BL translocation chromosomes, and have been named RT828-10 and RT828-11, respectively. The cytogenetic results also indicated that the pSc119.2 signals of 5AL were absent in both lines along with the pSc119.2 signals of 4AL of RT828-11. When inoculated with different stripe rust and powdery mildew isolates, both lines expressed high resistance to Puccinia striiformis f. sp. tritici and Blumeria graminis f. sp. tritici pathotypes, which are prevalent in China and are virulent on Yr9 and Pm8. The line RT828-11 also exhibited excellent agronomic traits in the field. The present study indicates that this rye variety may carry untapped variations that could potentially be used for wheat improvement.

Keywords: wheat, rye, translocation, disease resistance, agronomic traits, chromosome mutation

\section{INTRODUCTION}

Common wheat (Triticum aestivum L.) is 1 of the most important crops in the world. For higher yield and better resistance to diseases, many useful genes or factors have been introduced into wheat through chromosome translocation or substitution from many different relative genera (MolnárLáng et al., 2014; Feldman and Levy, 2015) such as Pm53, Yr40, and Yr42 from Aegilops spp. (Marais et al., 2009; Kuraparthy et al., 2009; Petersen et al., 2015), Pm40 and Yr50 from Thinopyrum spp. (Luo et al., 2009; Liu et al., 2013), Pm21 from Haynaldia villosa (Chen et al., 1995), YrSn0096 from Leymus mollis (Bao et al., 2012), and Pm2b from Agropyron (Ma et al., 2015). However, rye (Secale cereal L.) is the most important and valuable related species for the improvement of wheat genetics (Schlegel and Korzun, 1997; Rabinovich, 1998; Lelley et al., 2004; Ren et al., 2012). Since the 1950s, the 1RS chromosome arm was introduced into common wheat from the German rye 
variety 'Petkus' through a rye-wheat T1RS.1BL translocation line (Mettin et al., 1973; Schlegel and Korzun, 1997). Many resistant genes of rye were transferred into wheat, such as $\operatorname{Yr} 9, \operatorname{Pm} 8$, Lr26, and Sr31 (Mago et al., 2005; Ren et al., 2009). Moreover, the 1RS chromosome arm also harbors several genes could enhance the yield potential and wide range of environmental adaptability of wheat (Kumlay et al., 2003; Ren et al., 2012; Howell et al., 2014) Therefore, the rye-wheat 1RS.1BL translocation was used worldwide in wheat breeding programs (Rabinovich, 1998). However, the significant weakness of T1RS.1BL lines is its narrow genetic base, which is due to its single origin from Petkus rye (Baum and Appels, 1991; Schlegel and Korzun, 1997; Lelley et al., 2004; Ren et al., 2012).

Stripe rust and powdery mildew, which are caused by Puccinia striiformis f. sp. tritici (Pst) and Blumeria graminis f. sp. tritici $(B g t)$, respectively, are usually considered to be devastating diseases of wheat in cooler areas (Ren et al., 2009). Since the 1990s, due to its single origin, the 1RS chromosome arm derived from Petkus rye has not provided protection against the prevalence of virulent pathogens (Shi et al., 2001; Ren et al., 2009). So far, only a few other sources of $1 \mathrm{RS}$ were transferred into wheat (Ko et al., 2002; Mater et al., 2004; Ren et al., 2009, 2012; Molnár-Láng et al., 2010; Yang et al., 2014; Li et al., 2016a,b; Qi et al., 2016), and not every new translocation line could be used in wheat breeding programs (Ren et al., 2012). For more efficient use of the T1RS.1BL translocation in wheat breeding, Ren et al. (2012) suggested introduce a large amount of new genetic variation from many different rye sources into wheat.

In previous studies, polyploidization or chromosome translocation were considered as factors to induce the genome mutation or evolution (Ozkan et al., 2001; Tang et al., 2009; Li et al., 2016a). In the present study, we reported 2 new primary T1RS.1BL translocation lines which were developed from the crossbreeding of the wheat cultivar Mianyang11-1 (MY11-1) and the local Chinese rye variety Weining. We named these 2 lines RT828-10 and 828-11. Both lines were identified by FISH and molecular analysis, and showed high resistance to stripe rust and powdery mildew. Furthermore, these 2 lines could be excellent materials for use in wheat breeding programs.

\section{MATERIALS AND METHODS}

\section{Plant Materials}

Weining rye is a Chinese local rye variety collected from southwestern China. The common wheat cultivar Mianyang11 (MY11) was released in 1981, and is widely grown in southwestern China. MY11 contains the $k r 1$ gene, and therefore could be easily crossed with rye. A selfing line of MY11, which was named as MY11-1, was used in this study. Seeds of MY11-1 used for the crossing were produced by a single spike descent across several generations to create pure genetic stocks. The F1 seedlings of MY11-1 x Weining were soaked in $0.05 \%$ colchicine $+3 \%$ dimethyl sulfoxide for $8 \mathrm{~h}$ to produce the amphidiploid (C1). Then, the $\mathrm{C} 1$ plants were backcrossed to MY11-1 to produce monosomic wheat-rye addition lines.
A $1 \mathrm{R}$ monosomic addition line $98-828(2 \mathrm{n}=43=42 \mathrm{~W}+1$ '1 $\mathrm{R})$ was selected and continuously crossed with MY11-1 in an isolation field. Two primary translocation lines were selected from the progeny population. In southwestern China, MY111 is highly susceptible to stripe rust and powdery mildew. The T1RS.1BL translocation cultivar Chuan-nong10 (CN10), which inherited its $1 \mathrm{RS}$ chromosome from Petkus rye, was used as the control.

\section{Identification of Chromosomes}

Chromosome construction of RT828-10 and RT828-11 were identified by multi-color fluorescence in situ hybridization (MCFISH). Three probes, genomic DNA of Weining rye, pAs1, and $\mathrm{pSc} 119.2$ were used in the first MC-FISH experiment. The clone $6 c 6$ is a wheat-specific centromeric sequence, and the clone pMD-CEN-3 is a rye-specific centromeric sequence. These 2 probes were used in the second MC-FISH experiment to identify the centromere structure. Meanwhile, sequence CCCTAAACCCTAAACCCTAAACCCTAAA was used as a probe to identify telomeres. The labeling processes of probes and in situ hybridization were conducted according to Fu et al. (2013) and Tang et al. (2014a,b). Images were captured using an epifluorescence microscope (model BX51, Olympus, Center Valley, PA, USA) equipped with a cooled chargecoupled device camera, and operated with the software program HCIMAGE Live (version 2.0.1.5, Hamamatsu Corp., Sewickely, PA, USA).

\section{Molecular Analysis}

Total genomic DNA of 2 lines were isolated from young leaves by the surfactant cetyltrimethylammonium bromide. The seeds of RT828-10 and RT828-11 used in this experiment were collected from three different generations. O11B3 (5' -ggta ccaacaacaacaaccc- $\left.3^{\prime}\right)$ and O11B5 (5'-gttgctgctgaggttggttc- $\left.3^{\prime}\right)$ were used to detect the Glu-B3 gene on 1BS (Van Campenhout et al., 1995). $\omega$-sec-P1 ( $5^{\prime}$-accttcctcatctttgtcct- $\left.3^{\prime}\right)$ and $\omega$-sec-P2 $\left(5^{\prime}\right.$-ccgatgcctataccactact- $\left.3^{\prime}\right)$ were used to detect the Sec-1 gene on 1RS (Chai et al., 2006). The primer Gil-B1 (5'-gcagac ctgtgtcattggtc- $3^{\prime}, 5^{\prime}$-gatatagtggcagcaggatacg- $\left.3^{\prime}\right)$ was also used to detect the 1BS chromosome arms (Zhang et al., 2003). Furthermore, PrCEN-2 (5'-aatgatcttccacgacgacg-3', 5'-cctcg ttgggaaatggtgca- $\left.3^{\prime}\right)$ was designed according to nucleotides 1140-2090 of the pAWRC.1 sequence (GenBank accession No. AF245032), which was used to amplify a rye-specific band and to analyze the structure of the centromere of the T1RS.1BL chromosomes (Li et al., 2016b).

PCR was carried out in a Bio-Rad iCycler thermal cycler (Bio-Rad Laboratories, Inc., Hercules, CA, USA). DNA was amplified with a $0.5 \mathrm{U}$ Taq DNA polymerase enzyme, $1 \mathrm{X}$ buffer, $1.5 \mathrm{mM} \mathrm{MgCl}_{2}, 200 \mu \mathrm{M}$ dNTPs, $10 \mu \mathrm{mol}$ primer, and $50 \mathrm{ng}$ DNA in a total volume of $25 \mu \mathrm{L}$. After initial denaturation for $4 \mathrm{~min}$ at $94^{\circ} \mathrm{C}$, each cycle included $60 \mathrm{~s}$ of denaturation at $94^{\circ} \mathrm{C}, 60 \mathrm{~s}$ of annealing at $60^{\circ} \mathrm{C}$, and $2 \mathrm{~min}$ of extension at $72^{\circ} \mathrm{C}$. A final extension for $10 \mathrm{~min}$ at $72^{\circ} \mathrm{C}$ followed the 30 cycles. PCR reactions were stored at $4^{\circ} \mathrm{C}$ until their resolution by electrophoresis on $1 \%$ agarose gels stained with ethidium bromide. 


\section{Electrophoretic Detection of $\omega$-Secalin Proteins}

Detection of $\omega$-secalin proteins by acid polyacrylamide gel electrophoresis (A-PAGE) was conducted as described by Li et al. (2016a) with minor modifications. The seeds were pulverized, and then the gliadin was extracted by $25 \%(\mathrm{v} / \mathrm{v})$ ethylene chlorohydrin with $0.05 \%$ methyl green for $12 \mathrm{~h}$ at room temperature. The suspension was then centrifuged at $10,000 \mathrm{~g}$ for $10 \mathrm{~min}$ in a microfuge. Approximately $50 \mu \mathrm{L}$ of the supernatant was collected and used for electrophoresis. Gliadin samples were loaded onto $2 \mathrm{~mm}$ thick $10 \%$ acrylamide gel, and were buffered with $0.5 \%(\mathrm{w} / \mathrm{v}) N^{\prime} N$-methylenebisacrylamide at $\mathrm{pH}$ 3.1. The gliadin was fractionated at $500 \mathrm{~V}$ for approximately $180 \mathrm{~min}$. Then, gels were stained in $10 \%$ trichloroacetic acid (TCA) with 0.04\% Coomassie Brilliant Blue G-250 and destained in $12 \%$ TCA.

\section{Resistance Analysis}

RT828-10 and RT828-11 were examined for resistance to stripe rust and powdery mildew in the greenhouse and the field (Wan et al., 2004; Bariana and McIntosh, 1993). The Pst pathotypes CYR29 (virulent to $Y r 1,2,3,8,9,19,23$ ), CYR31 (virulent to Yr1, 2, 3, 6, 7, 9, 27), CYR32 (virulent to $Y r 1,2,3,4,6,9,27)$, and CYR33 (virulent to $\operatorname{Yr} 1,2,3,4,6,9,15,27)$ were considered of high frequency and toxicity in southwestern China. Three other Pst pathotypes, SY5, SY6, and HY8, have been virulent to many released wheat cultivars in China in the past 2 decades, and are also virulent to $\mathrm{Yr}$ 9. G22-9 is a new Pst pathogen and is prevalent in southwestern China, but in this experiment, all materials were resistant to it.

These 8 Pst pathotypes were used to inoculate the wheat plants. The Pst pathotypes were provided by the Plant Protection Institute, Gansu Academy of Agricultural Sciences, China. The Bgt isolate No. 9 was originally a single spore isolate culture collected in the field at Ya'an City, Sichuan, which was virulent to MY11-1, CN10 (Pm8), and Amigo (Pm17), and was used to inoculate RT828-10 and RT828-11 (Ren et al., 2009). Also, all plant materials were grown in the field and inoculated by mixed pathotypes of Pst and Bgt to determine the resistance response. Infection types (IT) of stripe rust were scored based on the 0-9 scale, as described by Wan et al. (2004). IT 0-3 are considered resistant, IT 4-6 are intermediate, and IT 7-9 are susceptible (Wan et al., 2004). The IT of powdery mildew was based on a 0-4 scale (Xie et al., 2004). Plants with an IT score of $0-2$ were considered resistant, while those with an IT score of 3-4 were considered susceptible, according to Bariana and McIntosh (1993).

\section{Field Experiments for Determining Yield Components}

All plants were grown in Qionglai District at Chengdu Plains, China in 2013-2015 following standard cultivation practices. Entries were arranged in a randomized, complete block design, in $3 \mathrm{~m}$ long plots, each consisting of four rows spaced $25 \mathrm{~cm}$ apart, at a plant density of 160 seedlings $/ \mathrm{m}^{2}$ with three replications. Plant height and length of spikes of 10 randomly chosen plants were determined immediately before harvest. Samples for yield components were collected from each plot. Then, $1 \mathrm{~m}$ lengths from the center rows were cut to determine the number of spikes per square meter, 1,000-kernel weight, spikelet number per spike, kernel number per spike, and kernel weight per spike. Then, plots were harvested for grain yield analysis. Grain was weighed to obtain yield estimates based on $12 \%$ moisture and grain yield $(\mathrm{kg} / \mathrm{ha})$, including the grain weight from the $1 \mathrm{~m}$ sample (Kim et al., 2004; Ren et al., 2012). Fungicide was applied to the seedlings and again at heading to control diseases and pests.

\section{Statistical Analysis}

Analysis of variance was performed for data of each character. The respective error term for the F-test was estimated using Sigmaplot 2001 software (SPSS Inc., Chicago, IL, USA). Least significant differences (LSD) were calculated for mean comparisons.

\section{RESULTS}

\section{Identification of the Chromosome Construction of Translocation Lines}

MC-FISH, PCR, and A-PAGE were used to identify the chromosome construction of lines RT828-10 and RT828-11. The results of MC-FISH (Figures $\mathbf{1 - 3})$ show that RT828-10 $(2 n=42)$ and RT828-11 $(2 n=42)$ contain an intact pair of wheatrye T1RS.1BL translocation chromosomes. Moreover, compared with their parent MY11-1, the signal patterns of pSc119.2 of 5AL were absent in both RT828-10 and RT828-11, and the signal patterns of pSc119.2 of the 4AL were absent in RT828-11 (Figures 1, 4). Because the seeds used in the present study were collected from three different generations, the results of the MCFISH indicated that RT828-10 and RT828-11 were cytogenetically stable, containing a pair of T1RS.1BL translocation chromosomes with several hereditable mutations on wheat chromosomes.

Specific molecular markers were also used for identify the construction of RT828-10 and RT828-11. Primer pairs O11B3 and O11B5 could amplify a specific 630 bp fragment band from the wheat $1 \mathrm{BS}$ chromosome arm. On the other hand, primer pairs $\omega$-sec-P1 and $\omega$-sec-P2 could amplify a specific 1,076 bp fragment band from the rye $1 \mathrm{RS}$ chromosome arm. These 2 primers were used together in 1 PCR reaction. Common wheat could amplify only a $630 \mathrm{bp}$ band, T1RS.1BL translocation lines could amplify only a 1,076 bp band, and heterozygous could amplify both bands. The PCR results indicated that only wheat parent MY11-1 could amplify a 630 bp band. All RT828-10 and RT828-11 lines collected from different generations could amplify a 1,076 bp band, but no 630 bp band was amplified (Figure 5).

The primer Gli-B1 could also amplify a specific fragment band of wheat, about $220 \mathrm{bp}$. The PCR results showed that all translocation plants could not amplify the band with the expect size except the wheat parent MY11-1 and Chinese spring (Figure 6). It was indicated that the 1BS of lines RT828-10 and RT828-11 were absent.

The primer PrCEN-2 could amplify a specific fragment band about 1,000 bp of the rye centromere repetitive sequence, and 

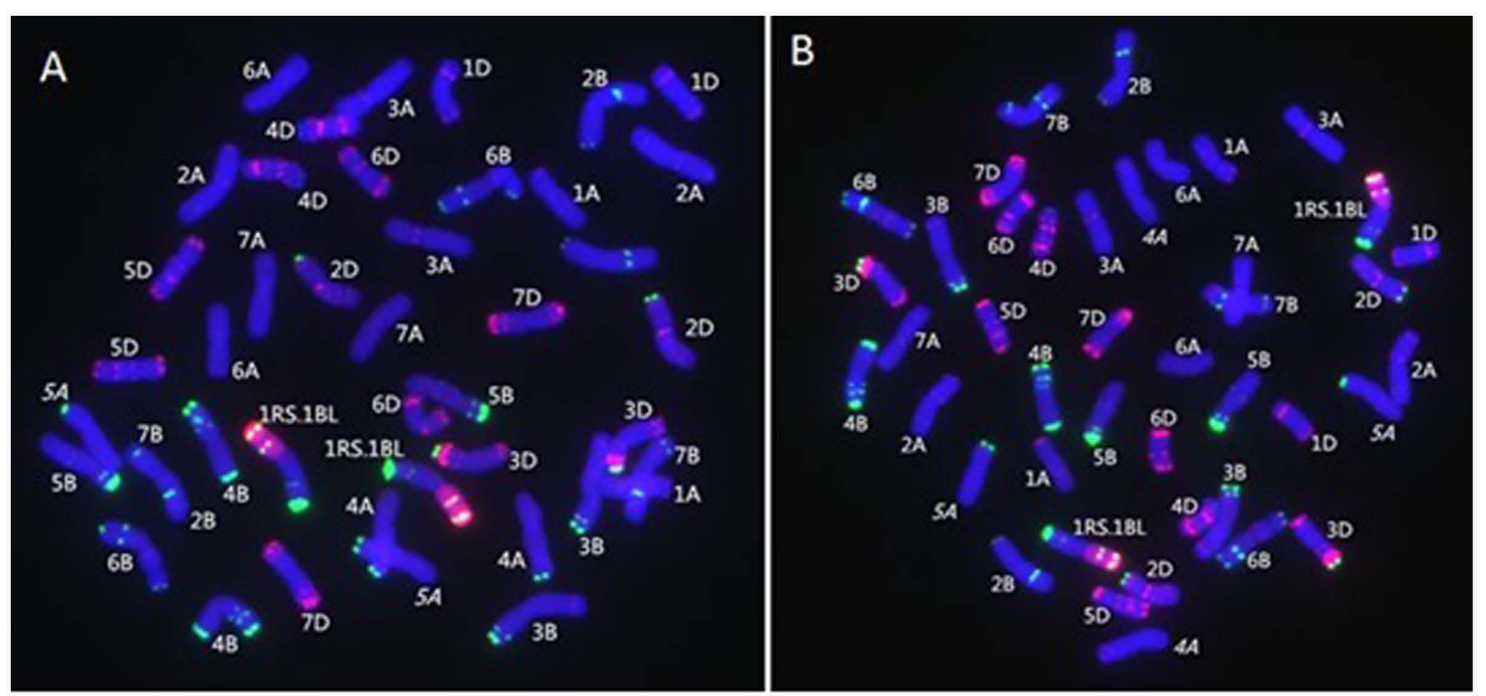

FIGURE 1 | MC-FISH of root tip chromosomes in wheat-rye translocation line RT828-10and RT828-11. (A) RT828-10 contains a pair of T1RS.1BL translocation chromosomes. The signal patterns of pSc119.2 on the middle of 5A chromosome long arm were absence. (B) RT828-11 contains a pair of T1RS.1BL translocation chromosomes. The signal patterns of pSc119.2 on the middle of 5A chromosome long arm and the end of 4A chromosome long arm were absence. Rye genome DNA(red), pSc119.2-1(green), pAs1-1(red).
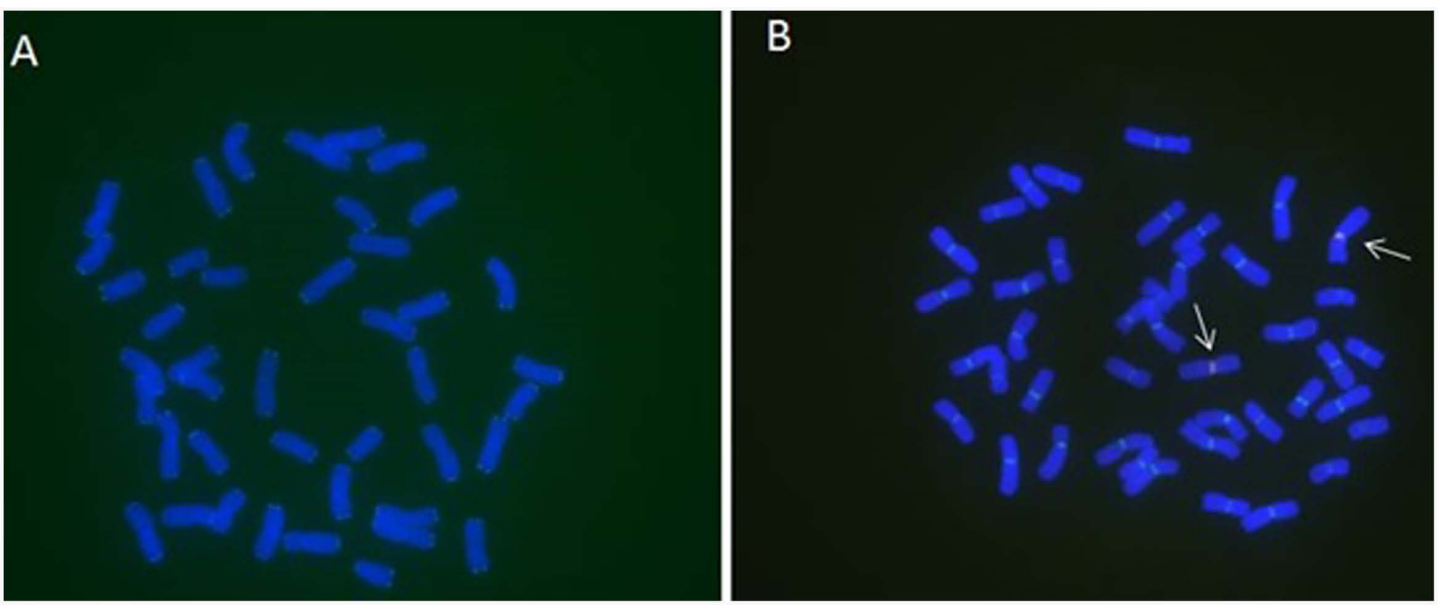

FIGURE 2 | MC-FISH of root tip chromosomes in wheat-rye translocation line RT828-10. (A) The signal patterns of telomere of RT828-10. (B) The construction of centromere of RT828-10. The signal patterns of pMD-CEN-3 and 6c6 joint together in the centromere region. The arrows indicated the translocation chromosomes.pMD-CEN-3(red), 6c6(green).

was used to determine the breakpoint and the fusion point of the chromosome of the translocation lines. The PCR results showed that all translocation plants amplified a band with the expect size (Figure 7). It was also indicated that the translocation line RT828-10 and RT828-11 contained the full 1RS arm of rye.

The w-secalin, which was encoded by the Sec-1 locus in the 1RS chromosome arm, could be used as a biochemistry marker to identify the $1 \mathrm{RS}$ chromosome arm. The specific bands of w-secalin were investigated by A-PAGE. All RT828-10 and RT828-11 samples exhibited normal expression for the genes at the Sec-1 locus (Figure 8). It was also observed that RT828-10 and RT828-11 contained the 1RS chromosome arms.

\section{Analysis for Resistance to Stripe Rust and Powdery Mildew}

Wheat parent MY11-1 was highly susceptible to 6 Pst pathotypes excluding HY8 and G22-9, while Weining rye was highly resistant to all Pst pathotypes (Table 1). Wheat cultivar CN10, whose 1RS chromosome arms came from the Russian wheat cultivar 'Aurora' (Yr9), were also highly susceptible to 5 Pst pathotypes except SY5, SY6, and G22-9 (Table 1). T1RS.1BL translocation line RT828-10 and RT828-11 showed high resistance to all Pst pathotypes (Table 1). On the other hand, MY11-1 and CN10 were highly susceptible to the Bgt isolate No. 9, but RT828-10 and RT828-11 showed high resistance to the isolate (Table 1). 

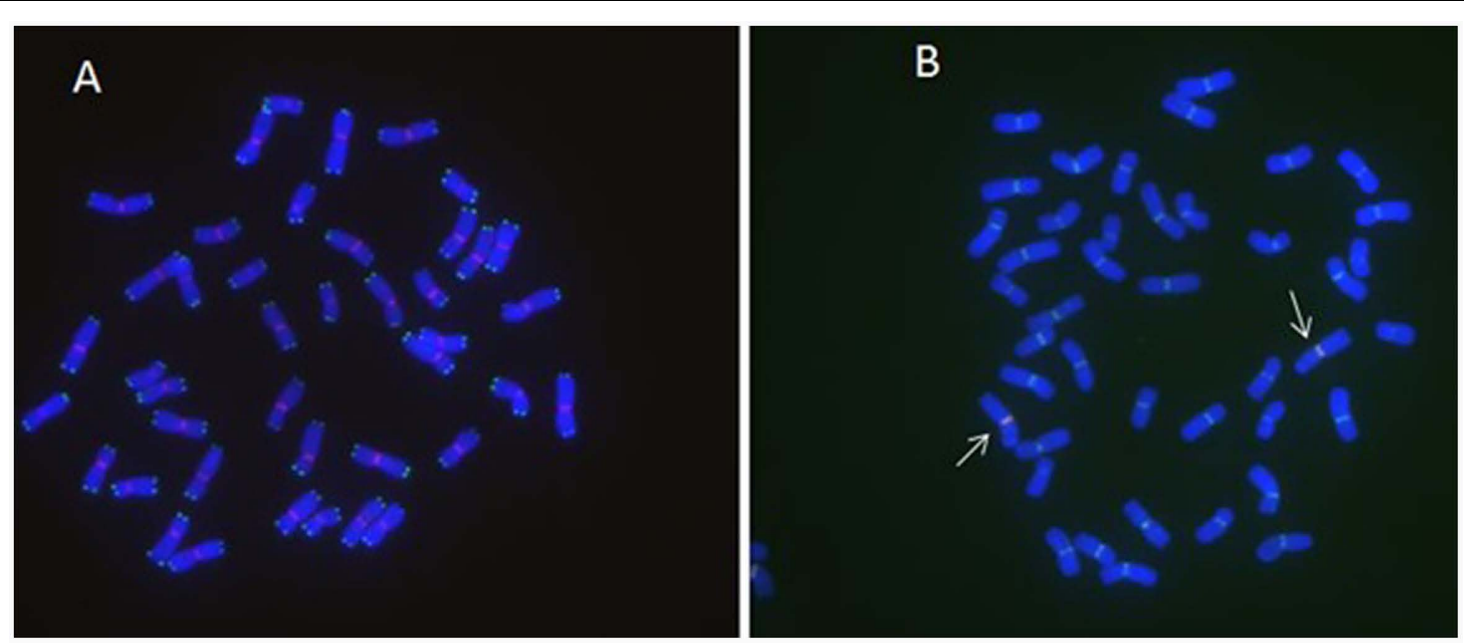

FIGURE 3 | MC-FISH of root tip chromosomes in wheat-rye translocation line RT828-11. (A) The construction of telomere and centromere of RT828-11. $6 \mathrm{c6}$ (red), sequence CCCTAAACCCTAAACCCTAAACCCTAAA (green). (B) The construction of centromere of RT828-11. The signal patterns of pMD-CEN-3 and 6c6 joint together in the centromere region. The arrows indicated the translocation chromosomes.pMD-CEN-3(red), 6c6(green).

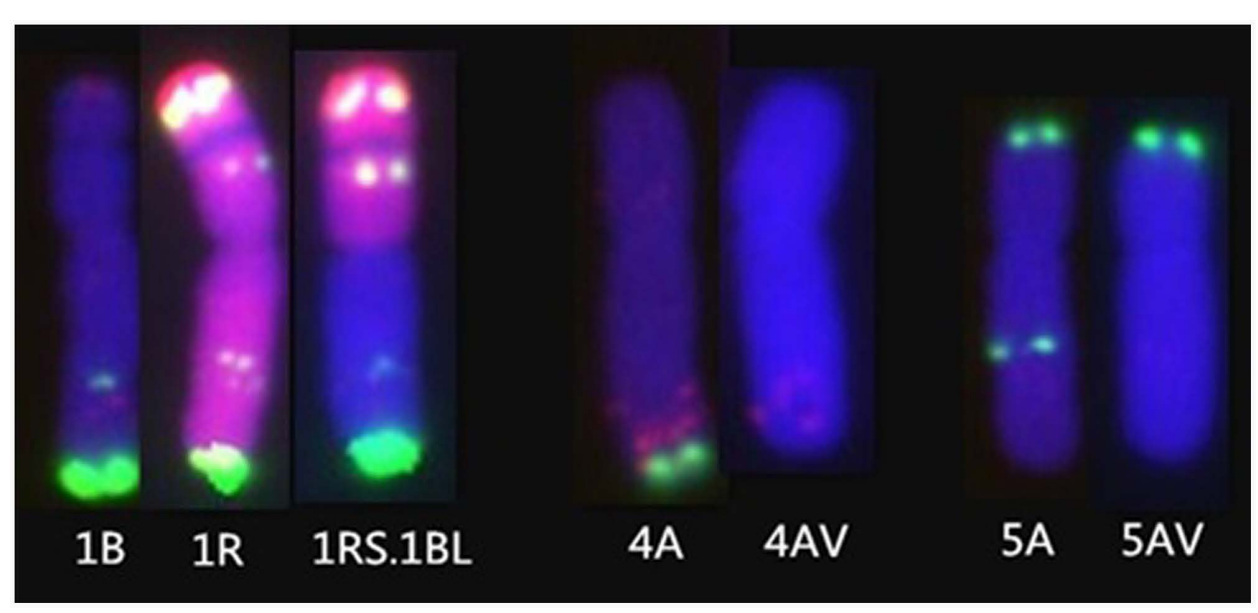

FIGURE 4 | The chromosome mutations of RT828-10 and RT828-11. (Left) The FISH patterns of 1B chromosome of MY11, 1Rchromosome of Weining rye, and the T1RS.1BL translocation chromosome derived from MY11 X Weining. (Middle) 4A chromosome of MY11 and 4A chromosome of RT828-11. The signal patterns of pSc119.2 of the 4A chromosome long arm of RT828-11 are absence. (Right) 5A chromosome of MY11 and 5A chromosome of RT828-10 and RT828-11. The signal patterns of pSc119.2 of the 5A chromosome long arm are absence.

Moreover, RT828-10 and RT828-11 also showed high resistance to stripe rust and powdery mildew in the field (Table $\mathbf{1}$ ).

\section{Effect of Chromosome Translocation on Agronomic Traits of Wheat}

Translocation lines RT828-10 and RT828-11 were derived from the same monosomic addition plant $\left(2 \mathrm{n}=43=21^{\prime \prime} \mathrm{W}+\right.$ $1 \mathrm{R})$, which originated from wheat MY11-1 and Weining rye. Compared with MY11-1, both translocation lines showed good agronomic traits. Specifically, in RT828-11, a significant increase $(P<0.05)$ was observed for plant height, spikelet number per spike, kernel number per spike, kernel weight per spike, 1,000kernel weight, number of spikes per square meter, and grain yield (Table 2). Compared with MY11-1, RT828-10 showed significantly lower kernel weight per spike and 1,000-kernel weight. However, the grain yield of RT828-10 was still higher than that of MY11-1 because of the significantly higher number of spikes per square meter. The variant translocation line RT828-11, which was lack of the pSc119.2 signal patterns of 4AL and 5AL (Figure 4), showed significantly better agronomic traits than another translocation line, RT828-10, which lacks the pSc119.2 signal of 5AL (Figure 4). The plant height, spikelet number per spike, kernel number per spike, kernel weight per spike, 1,000kernel weight, number of spikes per square meter and grain yield of RT828-11 were significantly higher than that of RT828-10 (Table 2). These results indicated that there are positive effects of the variant chromosome on agronomic traits. 


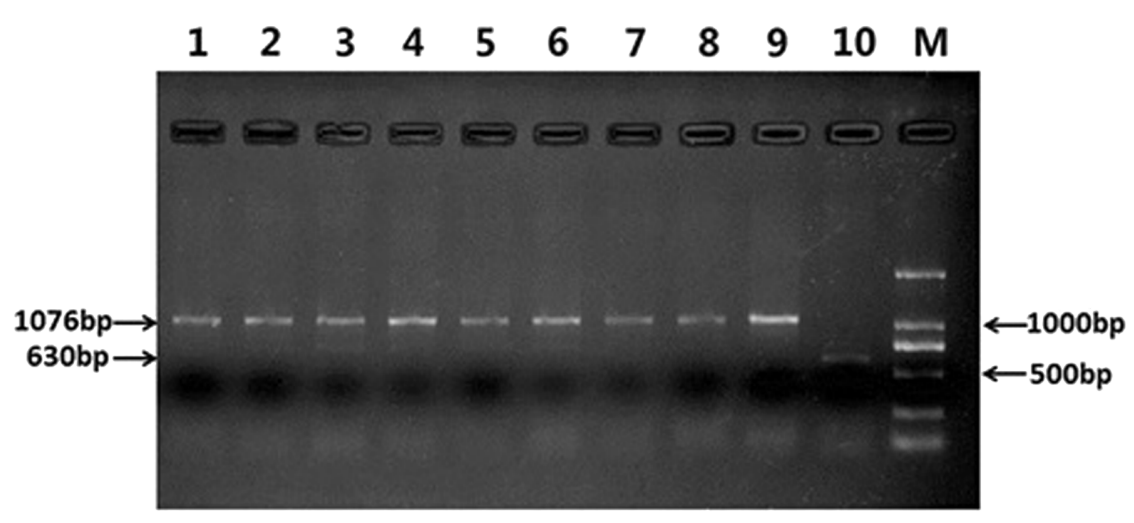

FIGURE 5 | Results of multiple-PCR by four specific primers: 011B3 and 011B5, $\omega$-sec-P1 and $\omega$-sec-P2. Lane 1-4 = RT828-10 from different generations; Lane 5-8 = RT828-11 from different generations; lane 9 = CN10; lane 10 = MY11; lane M = marker.

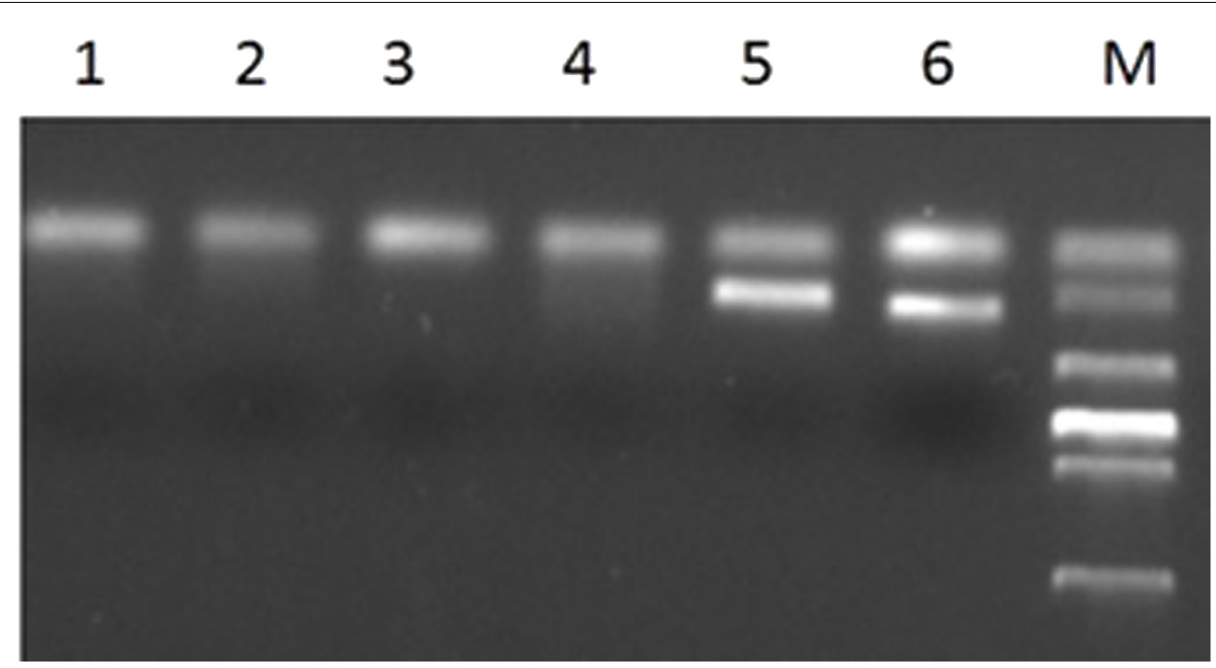

FIGURE 6 | PCR results of primer Gli-B1. Lane 1-2 = RT828-10 from different generations; lane 3-4 = RT828-11 from different generations; lane 5 = Mianyang11; lane 6 = Chinese Spring; lane $\mathrm{M}=$ marker.

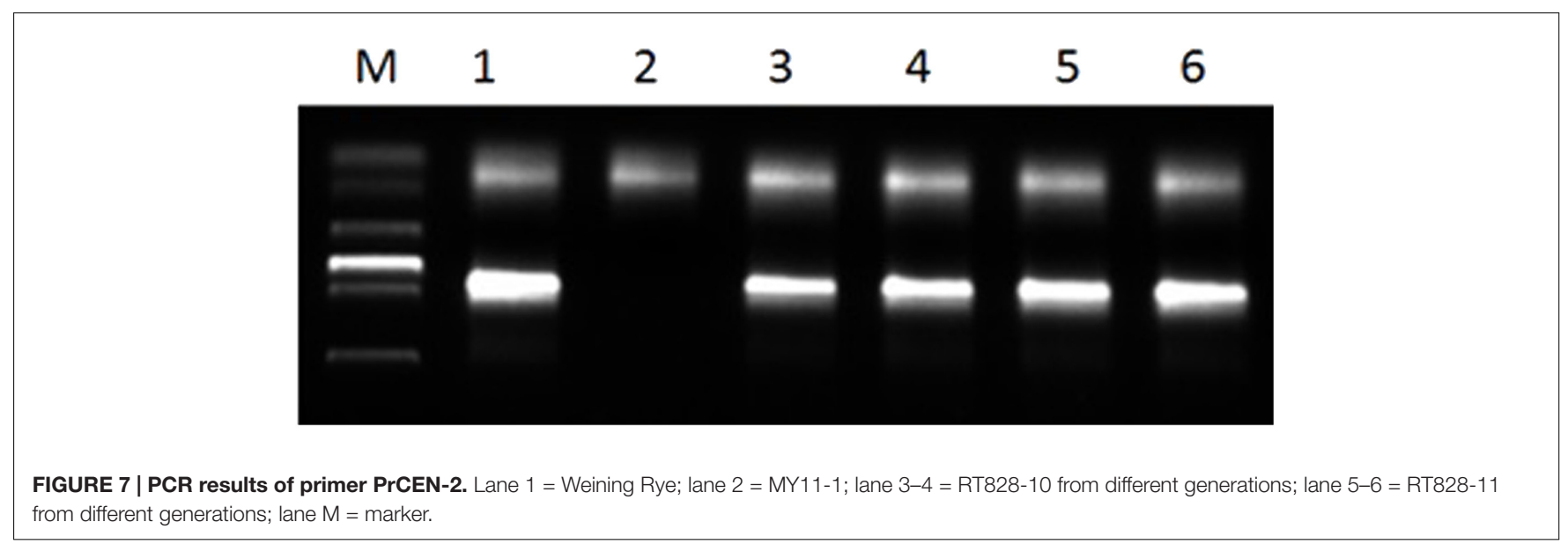




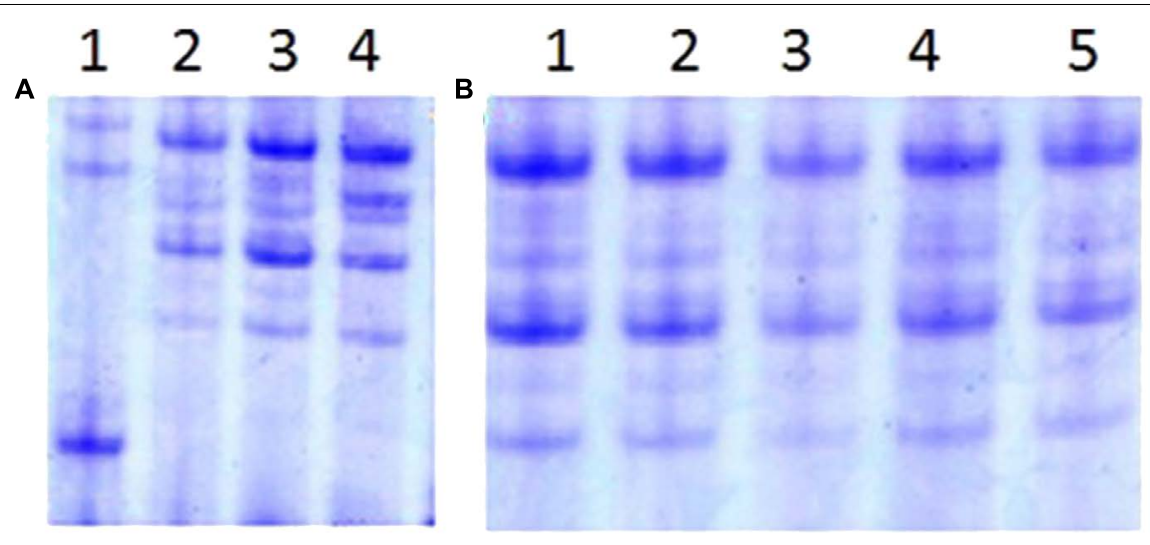

FIGURE 8 | A-PAGE separations of $\omega$-secalins and gliadins from RT828-10 and RT828-11. (A) Lane 1 = wheat parent MY11-1; lane 2-4 = RT828-10 from different generations; (B) Lane 1-5 = RT828-11 from different generations

TABLE 1 | Analysis of resistance to stripe rust in translocation lines and theirs' wheat parent when inoculated with epidemic pathotypes and isolates of Puccinia striiformis f. sp. Tritici and Blumeria graminis f. sp. tritici.

\begin{tabular}{|c|c|c|c|c|c|c|c|c|c|c|c|}
\hline \multirow[b]{2}{*}{$\begin{array}{l}\text { Translocation lines, } \\
\text { wheat parent and control }\end{array}$} & \multicolumn{9}{|c|}{ Pstpathotypes and isolates of PST } & \multicolumn{2}{|c|}{ Isolates of Bgt } \\
\hline & CYR29 & CYR31 & CYR32 & CYR33 & SY5 & SY6 & HY8 & G22-9 & In field & Isolate No.9 & In field \\
\hline RT828-10 & 0 & 0 & 0 & 0 & 0 & 0 & 0 & 0 & 0 & 0 & 0 \\
\hline RT828-11 & 0 & 0 & 0 & 0 & 0 & 0 & 0 & 0 & 0 & 0 & 0 \\
\hline MY11-1(wheat parent) & 8 & 8 & 8 & 8 & 8 & 6 & 0 & 0 & 7 & 4 & 4 \\
\hline Chuan-Nong10(CK) & 6 & 6 & 8 & 8 & 0 & 0 & 6 & 0 & 6 & 3 & 4 \\
\hline Weining rye & 0 & 0 & 0 & 0 & 0 & 0 & 0 & 0 & 0 & 0 & 0 \\
\hline
\end{tabular}

TABLE 2 | Comparisons of agronomic traits among RT828-10, RT828-11 and theirs' wheat parent.

\begin{tabular}{|c|c|c|c|c|c|c|c|c|}
\hline Lsines & $\mathrm{PH}(\mathrm{cm})$ & SLN (per spike) & KN (per spike) & KW (per spike) & TKW (g) & NS $\left(m^{-2}\right)$ & GY (kg/ha) & LS (cm) \\
\hline RT828-10 & $87.3 a$ & $20.6 a$ & $47.8 \mathrm{a}$ & $1.83 a$ & $38.3 a$ & $356.2 a$ & $6530.3 a$ & $8.9 a$ \\
\hline RT828-11 & $111.4 b$ & $23.1 b$ & $54.1 b$ & $2.58 c$ & $47.7 \mathrm{c}$ & $332.3 b$ & $8578.5 b$ & $9.4 a b$ \\
\hline Mianyang 11(wheat) & $85.8 a$ & $20.8 a$ & $47.9 a$ & $2.16 \mathrm{~b}$ & $45.0 \mathrm{~b}$ & $300.8 \mathrm{c}$ & $6484.8 \mathrm{a}$ & $10.1 b$ \\
\hline
\end{tabular}

$\overline{P H}=$ plant height, $S L N=$ spikelet number per spike, $K N=$ kernel number per spike, $K W=$ kernel weight per spike, TKW $=1,000-k e r n e l$ weight, $N S=$ number of spikes per square meter, GY = grain yield. $L S=$ length of spike. Values with the same letter in the same column do not differ significantly at $P<0.05$.

\section{DISCUSSION}

\section{Development and Identification of Variant Wheat-rye Translocation Lines}

T1RS.1BL translocation lines are not only important genetic resources for wheat breeding programs, but also materials for the study of genetics, physiology, and phytopathology of polyploidy plants (Eckardt, 2010; Wicker et al., 2003; De Storme and Mason, 2014). In the present study, 2 new primary T1RS.1BL translocation lines were developed from the progeny of the cross of rye variety Weining and wheat cultivar MY11-1. Multiple methods were used to screen the homozygote T1RS.1BL translocation lines from the enormous amount of progeny of the cross. A-PAGE was able to identify the w-secalin encoded by the Sec-1 locus of 1RS chromosome arm, and w-secalin was considered as a biochemistry marker of the 1RS chromosome arm. Thus, A-PAGE could be used as a tool to screen the presence of 1 RS chromosome arms in the progeny of wheat-rye crossings with enormous amounts of seeds. Although A-PAGE is efficient, it could not identify the existence form of the 1RS chromosome arms in the wheat genetic background. Moreover, several new T1RS.1BL translocation lines were expression deletion of gene Sec-1, and A-PAGE could not screen these particular T1RS.1BL translocation lines (Li et al., 2016a). C-banding and genomic 
in situ hybridization (GISH) have also been used to identify rye chromosomes in wheat genetic backgrounds. GISH showed that there were several rye chromatins in the wheat genome, but could not identify which rye chromosomes were introduced into the wheat genome. C-banding could identify most of the chromosomes of rye and wheat, but it was too difficult to conduct C-banding and obtain high resolution pictures. In this study, MC-FISH was used to confirm the construction of wheat lines RT828-10 and RT828-11.

The probe pAs1 can identify the D-genome chromosomes and was able to show different signal patterns on $1 \mathrm{~A}, 2 \mathrm{~A}, 3 \mathrm{~A}$, $4 \mathrm{~A}, 6 \mathrm{~A}, 7 \mathrm{~A}, 1 \mathrm{~B}, 2 \mathrm{~B}, 3 \mathrm{~B}, 6 \mathrm{~B}$, and $7 \mathrm{~B}$ chromosomes of wheat (Schneider et al., 2003; Tang et al., 2014a,b). The probe pSc119.2 could identify the B-genome and rye chromosomes, and also showed different signal patterns on the $2 \mathrm{~A}, 4 \mathrm{~A}, 5 \mathrm{~A}, 2 \mathrm{D}, 3 \mathrm{D}$, and $4 \mathrm{D}$ chromosomes of wheat (Schneider et al., 2003; Contento et al., 2005; Tang et al., 2014a,b). Multiple probes were used in MC-FISH. Furthermore, the mixed probes of pAs1, pSc119.2, and rye genomic DNA could directly distinguish different wheat and rye chromosomes in 1 cell (Tang et al., 2014a,b; Ren et al., 2016). Compared with FISH or C-banding, MC-FISH was much more efficient and precise. Our MC-FISH results indicated that both lines were T1RS.1BL translocation lines. It also showed that both lines lacked the signal patterns of pSc119.2 of 5AL, and that RT828-11 simultaneously lacked the signal patterns of pSc119.2 of 4AL. These chromosome mutants could be induced during the progress of chromosome translocation. The occurrence of genes or DNA fragment mutants induced with the chromosomal variation, including translocation, substitution, addition, and polyploidization, can be considered accompanying mutations (Li et al., 2016a), and the accompanying mutations of the evolutionarily significant translocations are remarkable resources for plant improvement.

Moreover, molecular markers were used to identify translocation chromosomes. Several molecular markers were developed, and were specific for an individual locus or genes of wheat or rye, such as O11B3/B5 and $\omega$-sec-P1/P2 (Van Campenhout et al., 1995; Chai et al., 2006). It was efficient to use these markers to detect rye chromatin in the wheat genome. In the present study, our results indicated that RT828-10 and RT828-11 are stable new primary T1RS.1BL translocation lines.

Tang et al. (2009) indicated that allopolyploidization could induce immediate microsatellite evolution, and Li et al. (2016a) reported that the Sec-1 gene, which is located on 1RS, was mutant after chromosome translocation. Additionally, Tang et al. (2014b) reported that the signal patterns of pSc119.2 of 5AL were mutant after polyploidization. It was suggested that the mutant of chromosome structure could be induced by polyploidization and translocation. In the present study, compared with the wheat parent MY11-1, the signal patterns of pSc119.2 of 5AL were mutant in both translocation lines, and signal patterns of $4 \mathrm{AL}$ were also mutant in RT828-11 (Figures 1, 4).

\section{Resistance to Stripe Rust and Powdery Mildew}

Hundreds of wheat cultivars have been released from the globally used T1RS.1BL translocation line Aurora, which originated from
Petkus rye (Rabinovich, 1998). Therefore, the 1RS chromosome arms lacked genetic diversity (Schlegel and Korzun, 1997; Ren et al., 2009, 2012). Since the 1990s, due to the prevalence of virulent pathotypes, virulence to $\operatorname{Yr} 9$ and $P m 8$ have not provided protection to the respective pathogens anymore (Ren et al., 2009). Several scientists tried to transfer new sources of 1RS chromosomes of rye into common wheat. These new T1RS.1BL translocation lines showed diversity-resistant patterns to rust stripe and powdery mildew. However, few new translocation lines showed both high resistance to these two diseases and could be used in the wheat breeding program (Ko et al., 2002; Yang et al., 2014; Li et al., 2016b; Qi et al., 2016).

Rye is a cross-pollinated plant with high genetic diversity in the population of a variety. It was suggested that the abundance of variations could be consist in rye varieties (Ren et al., 2011). In the present study, 2 new stable primary T1RS.1BL translocation lines, RT828-10 and RT828-11, derived from Chinese rye variety Weining, showed high resistance to 8 Pst pathotypes that are prevalent in China. RT828-10 and RT828-11 also showed high resistance to Bgt isolate, which is virulent to Pm8 and Pm17. Furthermore, RT828-10 and RT82811 exhibited resistance to the prevalent pathotypes to these two diseases more than the T1RS.1BL translocation cultivar CN10, which harbors genes $Y r 9$ and $P m 8$. Since the wheat parent MY11-1 was highly susceptible to stripe rust and powdery mildew, it is obvious that the resistant genes in RT828-10 and RT828-11 must be located on the 1RS chromosome arms, which were derived from Weining rye. The new resistance genes provided better protection to diseases than $Y r 9, P m 8$, and Pm17.

\section{The Effect of Agronomic Traits of Variation Translocation Lines}

Both translocation lines showed good agronomic traits, especially RT828-11, which showed a significant increase over its wheat parent MY11-1. Although RT828-10 and RT828-11 were T1RS.1BL translocation lines with variation, they had a normal phenotype in the field, similar to their wheat parent and other T1RS.1BL translocation lines also derived from MY11-1. The genetic effects of chromosome variation could be detected by comparing these 2 lines with wheat parent MY11-1. The 1RS.1BL translocations were considered favorable for agronomic performance (Villareal et al., 1995; Ren et al., 2012); however, the effects of the 1RS.1BL translocation were not consistent for grain yield. Several studies reported no significant effect on grain yield in 1RS.1BL translocation lines (McKendry et al., 1996; Singh et al., 1998), but in another study, the 1RS source was suggested to be responsible for yield enhancement (Kim et al., 2004) because significant interactions between wheat and rye sources existed for grain yield (Jung and Lelley, 1985; Ren et al., 2012). The 1RS.1BL translocations increased grain yield only in specific combinations of $1 \mathrm{RS}$ and $1 \mathrm{BL}$. In the present study, we found that only RT828-11 remarkably increased the agronomic performance. Introduction of the 1RS arm significantly improved several agronomic traits in RT828-11, such as PH, SLN, KN, KW, TKW, NS, and GY (Table 2). 


\section{AUTHOR CONTRIBUTIONS}

TR and ZL designed this work. TR, ZT, SF did the MC-FISH. TR, ZL did the molecular analyze and A-PAGE. TR, ZR did the resistance analyze. TR, ZR, BY, FT did the field work. TR and ZL wrote the manuscript.

\section{REFERENCES}

Bao, Y., Wang, J., He, F., Ma, H., and Wang, H. (2012). Molecular cytogenetic, identification of a wheat (Triticum aestivum)-American dune grass (Leymus mollis) translocation line resistant to stripe rust. Genet. Mol. Res. 11, 3198-3206. doi: 10.4238/2012.May.22.2

Bariana, H. S., and McIntosh, R. A. (1993). Cytogenetic studies in wheat. XV. Location of rust resistance genes in VPM1 and their genetic linkage with other disease resistance genes in chromosome 2A. Genome 36, 476-482. doi: 10.1139/ g93-065

Baum, M., and Appels, R. (1991). The cytogenetic and molecular architecture of chromosome 1R-one of the most widely utilized sources of alien chromatin in wheat varieties. Chromosoma 101, 1-10. doi: 10.1007/BF00360680

Chai, J. F., Zhou, R. H., Jia, J. Z., and Liu, X. (2006). Development and application of a new codominant PCR marker for detecting 1BL.1RS wheat-rye chromosome translocations. Plant Breed. 125, 302-304. doi: 10.1111/j.1439-0523.2006. 01186.x

Chen, P. D., Qi, L. L., Zhou, B., Zhang, S. Z., and Liu, D. J. (1995). Development and molecular cytogenetic analysis of wheat-Haynaldia villosa 6VS/6AL translocation lines specifying resistance to powdery mildew. Theor. Appl. Genet. 91, 1125-1128. doi: 10.1007/BF00223930

Contento, A., Heslop-Harrison, J. S., and Schwarzacher, T. (2005). Diversity of a major repetitive DNA sequence in diploid and polyploidy Triticeae. Cytogenet. Genome Res. 109, 34-42. doi: 10.1159/000082379

De Storme, N., and Mason, A. (2014). Plant speciation through chromosome instability and ploidy change: cellular mechanisms, molecular factors and evolutionary relevance. Curr. Plant Biol. 1, 10-33. doi: 10.1016/j.cpb.2014. 09.002

Eckardt, N. A. (2010). Evolution of domesticated bread wheat. Plant Cell 22, 993-993. doi: 10.1105/tpc.110.220410

Feldman, M., and Levy, A. A. (2015). "Origin and evolution of wheat and related Triticeae Species," in Alien Introgression in Wheat, eds M. Molnar-Lang, C. Carla, and D. Jaroslav (Cham: Springer International Publishing), 21-76.

Fu, S., Yang, M., Fei, Y., Tan, F., Ren, Z., Yan, B., et al. (2013). Alterations and abnormal mitosis of wheat chromosomes induced by wheat-rye monosomicaddition lines. PLoS ONE 8:e70483. doi: 10.1371/journal.pone. 0070483

Howell, T., Hale, I., Jankuloski, L., Bonafede, M., Gilbert, M., and Dubcovsky, J. (2014). Mapping a region within the $1 \mathrm{RS} .1 \mathrm{BL}$ translocation in common wheat affecting grain yield and canopy water status. Theor. Appl. Genet. 127, 2695-2709. doi: 10.1007/s00122-014-2408-6

Jung, C., and Lelley, T. (1985). Genetic interaction between wheat and rye genomes in triticale. Theor. Appl. Genet. 70, 427-432. doi: 10.1007/BF00273750

Kim, W., Johnson, J. W., Baenziger, P. S., Lukaszewski, A. J., and Gaines, C. S. (2004). Agronomic effect of wheat-rye translocation carrying rye chromatin (1R) from different sources. Crop Sci. 44, 1254-1258. doi: 10.2135/cropsci2004. 1254

Ko, J. M., Seo, B. B., Suh, D. Y., Do, G. S., Park, D. S., and Kwack, Y. H. (2002). Production of a new wheat line possessing the 1BL.1RS wheat-rye translocation derived from Korean rye cultivar Paldanghomil. Theor. Appl. Genet. 104, 171-176. doi: 10.1007/s00122-001-0783-2

Kumlay, A. M., Baenziger, P. S., Gill, K. S., Shelton, D. R., Graybosch, R. A., Lukaszewski, A. J., et al. (2003). Understanding the effect of rye chromatin in bread wheat. Crop Sci. 43, 1643-1651. doi: 10.2135/cropsci2003.1643

Kuraparthy, V., Sood, S., and Gill, B. S. (2009). Molecular genetic description of the cryptic wheat-Aegilops geniculata introgression carrying rust resistance genes Lr57 and Yr40 using wheat ESTs and synteny with rice. Genome 52, 1025-1036. doi: $10.1139 / \mathrm{G} 09-076$

\section{ACKNOWLEDGMENTS}

We gratefully acknowledge the financial support from the National Natural Science Foundation of China (\#31271722). We also acknowledge excellent technical assistance provided by H. Q. Zhang.

Lelley, T., Eder, C., and Grausgruber, H. (2004). Influence of 1BL.1RS wheat-rye chromosome translocation on genotype by environment interaction. J. Cereal Sci. 39, 313-320. doi: 10.1016/j.jcs.2003.11.003

Li, Z., Ren, T., Yan, B., Tan, F., Yang, M., and Ren, Z. (2016a). A mutant with expression deletion of gene Sec-1 in a 1RS.1BL line and its effect on production quality of wheat. PLoS ONE 11:e0146943. doi: 10.1371/journal.pone.0146943

Li, Z., Ren, Z., Tan, F., Tang, Z., Fu, S., Yan, B., et al. (2016b). Molecular cytogenetic characterization of new wheat-rye $1 \mathrm{R}(1 \mathrm{~B})$ substitution and translocation lines from a Chinese Secale cereal L. Aigan with resistance to stripe rust. PLoS ONE 11:e0163642. doi: 10.1371/journal.pone.0163642

Liu, J., Chang, Z., Zhang, X., Yang, Z., Li, X., Jia, J., et al. (2013). Putative Thinopyrum intermedium-derived stripe rust resistance gene Yr50 maps on wheat chromosome arm 4BL. Theor. Appl. Genet. 126, 265-274. doi: 10.1007/ s00122-012-1979-3

Luo, P. G., Luo, H. Y., Chang, Z. J., Zhang, H. Y., Zhang, M., and Ren, Z. L. (2009). Characterization and chromosomal location of $P m 40$ in common wheat: a new gene for resistance to powdery mildew derived from Elytrigia intermedium. Theor. Appl. Genet. 118, 1059-1064. doi: 10.1007/s00122-009-0962-0

Ma, P., Xu, H., Xu, Y., Li, L., Qie, Y., Luo, Q., et al. (2015). Molecular mapping of a new powdery mildew resistance gene $P m 2 b$ in Chinese breeding line KM2939. Theor. Appl. Genet. 128, 613-622. doi: 10.1007/s00122-015-2457-5

Mago, R., Miah, H., Lawrence, G. J., Wellings, C. R., Spielmeyer, W., Bariana, H. S., et al. (2005). High-resolution mapping and mutation analysis separate the rust resistance genes $\operatorname{Sr} 31, \operatorname{Lr} 26$ and $\operatorname{Yr} 9$ on the short arm of rye chromosome 1. Theor. Appl. Genet. 112, 41-50. doi: 10.1007/s00122-005-0098-9

Marais, F., Marais, A., Mccallum, B., and Pretorius, Z. (2009). Transfer of leaf rust and stripe rust resistance genes Lr62 and Yr42 from Aegilops neglecta Req. ex Bertol. to common wheat. Crop Sci. 49, 871-879. doi: 10.2135/cropsci2008.06. 0317

Mater, Y., Baenziger, S., Gill, K., Graybosch, R., Whitcher, L., Baker, C., et al. (2004). Linkage mapping of powdery mildew and greenbug resistance genes on recombinant 1RS from 'Amigo' and 'Kavkaz' wheat-rye translocations of chromosome 1RS.1AL. Genome 47, 292-298. doi: 10.1139/g03-101

McKendry, A. L., Tague, D. N., and Miskin, K. E. (1996). Effect of 1BL.1RS on agronomic performance of soft red winter wheat. Crop Sci. 36, 844-847. doi: 10.2135/cropsci1996.0011183X003600040003x

Mettin, D., Bluthner, W. D., and Schlegel, G. (1973). "Additional evidence on spontaneous 1B/1R wheat-rye substitutions and translocation," in Proceedings of the 4th International Wheat Genetics Symposium, eds E. R. Sears and L. M. S. Sears (Columbia, MO: Agriculture Experiment Station), 179-184.

Molnár-Láng, M., Cseh, A., Szakács, É., and Molnár, I. (2010). Development of a wheat genotype combining the recessive crossability alleles $k r 1 k r 1 k r 2 k r 2$ and the 1BL.1RS translocation, for the rapid enrichment of 1RS with new allelic variation. Theor. Appl. Genet. 120, 1535-1545. doi: 10.1007/s00122-010-1274-0

Molnár-Láng, M., Molnár, I., Szakács, E., Linc, G., and Bedö, Z. (2014). "Production and molecular cytogenetic identification of wheat-alien hybrids and introgression Lines," in Genomics of Plant Genetic Resources, eds T. Roberto, G. Andreas, and F. Emile (Dordrecht: Springer Science+Business Media), 255-283.

Ozkan, H., Levy, A. A., and Feldman, M. (2001). Allopolyploidy-induced rapid genome evolution in the wheat (Aegilops-Triticum) group. Plant Cell 13, 1735-1747. doi: 10.1105/tpc.13.8.1735

Petersen, S., Lyerly, J. H., Worthington, M. L., Parks, W. R., Cowger, C., Marshall, D. S., et al. (2015). Mapping of powdery mildew resistance gene Pm53 introgressed from Aegilops speltoides into soft red winter wheat. Theor. Appl. Genet. 128, 303-312. doi: 10.1007/s00122-014-2430-8

Qi, W., Tang, Y., Zhu, W., Li, D., Diao, C., Xu, L., et al. (2016). Molecular cytogenetic characterization of a new wheat-rye 1BL1RS translocation line 
expressing superior stripe rust resistance and enhanced grain yield. Planta 244, 405-416. doi: 10.1007/s00425-016-2517-3

Rabinovich, S. V. (1998). Importance of wheat-rye translocations for breeding modern cultivars of Triticum aestivum L. Euphytica 100, 323-340. doi: 10.1023/ A:1018361819215

Ren, T., Li, Z., Yan, B., Tan, F., Tang, Z., Fu, S., et al. (2016). De novo balanced complex chromosome rearrangements involving chromosomes $1 \mathrm{~B}$ and $3 \mathrm{~B}$ of wheat and 1R of rye. Genome 59, 1076-1084. doi: 10.1139/gen-2016-0112

Ren, T. H., Chen, F., Yan, B. J., Zhang, H. Q., and Ren, Z. L. (2012). Genetic diversity of wheat-rye 1BL.1RS translocation lines derived from different wheat and rye sources. Euphytica 183, 133-146. doi: 10.1007/s10681-011-0412-3

Ren, T. H., Chen, F., Zou, Y. T., Jia, Y. H., Zhang, H. Q., Yan, B. J., et al. (2011). Evolutionary trends of microsatellites during the speciation process and phylogenetic relationships within the genus Secale. Genome 54, 316-326. doi: 10.1139/g10-121

Ren, T. H., Yang, Z. J., Yan, B. J., Zhang, H. Q., Fu, S. L., and Ren, Z. L. (2009). Development and characterization of a new 1BL.1RS translocation line with resistance to stripe rust and powdery mildew of wheat. Euphytica 169, 207-213. doi: 10.1007/s10681-009-9924-5

Schlegel, R., and Korzun, V. (1997). About the origin of 1RS.1BL wheatrye chromosome translocations from Germany. Plant Breed. 116, 537-540. doi: 10.1111/j.1439-0523.1997.tb02186.x

Schneider, A., Linc, G., Molnár-Láng, M., and Graner, A. (2003). Fluorescence in situ hybridization polymorphism using two repetitive DNA clones in different cultivars of wheat. Plant Breed. 122, 396-400. doi: 10.1046/j.1439-0523.2003. 00891.x

Shi, Z. X., Chen, X. M., Line, R. F., Leung, H., and Wellings, C. R. (2001). Development of resistance gene analog polymorphism markers for the $\mathrm{Yr} 9$ gene resistance to wheat stripe rust. Genome 44, 509-516. doi: 10.1139/gen-44-4-509

Singh, R. P., Huerta-Espino, J., Rajaram, S., and Crossa, J. (1998). Agronomic effects from chromosome translocations 7DL.7Ag and 1BL.1RS in spring wheat. Crop Sci. 38, 27-33. doi: 10.2135/cropsci1998.0011183X003800010005x

Tang, Z., Fu, S., Ren, Z., and Zou, Y. (2009). Rapid evolution of simple sequence repeat induced by allopolyploidization. J. Mol. Evol. 69, 217-228. doi: 10.1007/ s00239-009-9261-2

Tang, Z., Li, M., Chen, L., Wang, Y., Ren, Z., and Fu, S. (2014a). New types of wheat chromosomal structural Variations in derivatives of wheat-rye hybrids. PLoS ONE 9:e110282. doi: 10.1371/journal.pone.0110282

Tang, Z., Yang, Z., and Fu, S. (2014b). Oligonucleotides replacing the roles of repetitive sequences pAs1, pSc119.2, pTa-535, pTa71, CCS1, and pAWRC.1 for FISH analysis. J. Appl. Genet. 55, 313-318. doi: 10.1007/s13353-0140215-z

Van Campenhout, S., Vander Stappen, J., Sagi, L., and Volckaert, G. (1995). Locusspecific primers for LMW glutenin genes on each of the group 1 chromosomes of hexaploid wheat. Theor. Appl. Genet. 91, 313-319. doi: 10.1007/BF00220893

Villareal, R. L., Toro, E. D., Mujeeb-Kazi, A., and Rajaram, S. (1995). The 1BL/1RS chromosome translocation effect on yield characteristics in a Triticum aestivum L. cross. Plant Breed. 114, 497-500. doi: 10.1111/j.1439-0523.1995.tb00843.x

Wan, A., Zhao, Z., Chen, X., He, Z., Jin, S., Jia, Q., et al. (2004). Wheat stripe rust epidemic and virulence of Puccinia striiformis f. sp. tritici in China in 2002. Plant Dis. 88, 896-904. doi: 10.1094/PDIS.2004.88.8.896

Wicker, T., Yahiaoui, N., Guyot, R., Schlagenhauf, E., Liu, Z. D., Dubcovsky, J., et al. (2003). Rapid genome divergence at orthologous low molecular weight glutenin loci of the A and Am genomes of wheat. Plant Cell 15, 1186-1197. doi: 10.1105/tpc.011023

Xie, C. J., Sun, Q. X., Ni, T., Nevo, E., and Fahima, F. (2004). Identification of resistance gene analogue markers closely linked to wheat powdery mildew resistance gene Pm31. Plant Breed. 123, 198-200. doi: 10.1046/j.1439-0523. 2003.00940.x

Yang, M. Y., Ren, T. H., Yan, B. J., Li, Z., and Ren, Z. L. (2014). Diversity resistance to Puccinia striiformis $\mathrm{f}$. sp Tritici in rye chromosome arm 1RS expressed in wheat. Genet. Mol. Res. 13, 8783-8793. doi: 10.4238/2014.October.27.20

Zhang, L., He, Z., Lu, M., Pang, B., Zhang, X., Xia, L., et al. (2003). Identification of 1BL/1RS translocation via multiplex PCR, markers of Glu-B3, Gli-B1 and SEC-1b in common wheat. Sci. Agric. Sin. 36, 1566-1570.

Conflict of Interest Statement: The authors declare that the research was conducted in the absence of any commercial or financial relationships that could be construed as a potential conflict of interest.

The reviewer $\mathrm{AB}$ and handling Editor declared their shared affiliation, and the handling Editor states that the process nevertheless met the standards of a fair and objective review.

Copyright (c) 2017 Ren, Tang, Fu, Yan, Tan, Ren and Li. This is an open-access article distributed under the terms of the Creative Commons Attribution License (CC BY). The use, distribution or reproduction in other forums is permitted, provided the original author(s) or licensor are credited and that the original publication in this journal is cited, in accordance with accepted academic practice. No use, distribution or reproduction is permitted which does not comply with these terms. 